\title{
Attention-deficit/hyperactivity disorder in perspective
}

\author{
Luis Augusto Rohde
}

Published online: 3 September 2010

(C) Springer-Verlag 2010

Attention-deficit/hyperactivity disorder (ADHD) is not only one of the most frequent child neuropsychiatric disorder [9], but also one of the most investigated conditions in child and adolescent mental health [7]. Interest in the nosology of ADHD is renewed owing to the preliminary ADHD criteria recently presented by the ADHD and Disruptive Behavior Disorder working group for DSM-V of the American Psychiatric Association.

Among several aspects considered for review in the criteria [10], two are directly or indirectly addressed by papers in this issue of our journal. DSM-IV criteria exclude ADHD diagnosis in the presence of pervasive development disorders (PDD). A recent body of literature challenges this notion, documenting high comorbidity between the two disorders (see, for instance, [11]). Ghanizadeh [2] performed exploratory and confirmatory factor analyses on DSM-IV ADHD and autistic spectrum disorder (ASD) symptoms from validated scales in a community sample of 1600 school-age children. His findings suggest that the high rate of co-morbidity between ADHD and ASD is probably not due to the overlapping diagnostic criteria of ADHD and ASD.

One of the main drives for the revision of the DSM-IV criteria for mental disorders was the promise of a new frame in psychiatric nosology by the incorporation of a more pathophysiological approach resulting in a potential presence of biological markers as part of the diagnostic criteria [3]. Theoretically, ADHD would be a potential

L. A. Rohde ( $\square)$

ADHD Outpatient Program, Department of Psychiatry,

Hospital de Clinicas de Porto Alegre,

Federal University of Rio Grande do Sul, Rua Ramiro Barcelos,

2350, 2nd Floor, Room 2201, Porto Alegre, Brazil

e-mail: 1rohde@terra.com.br candidate to be a "prime star" for this revolution in the classificatory system! The high heritability of the disorder is well established, and large amounts of new data have documented the neurobiological basis of ADHD [5, 13]. However, after more than a decade of intense research on ADHD molecular genetics, neuropsychology and neuroimaging, we are still missing clear biological markers with sufficient sensitivity and specificity to be incorporated in the classificatory system [10]. In addition, the role of environmental risk factors or correlates in the pathophysiology of this heterogenic disorder is not completely understood. Two papers in this issue might help to enlarge our knowledge on potential environmental factors associated with ADHD. Motlagh et al. [8] found that mothers of children with ADHD reported both higher rates of heavy smoking and higher levels of severe psychological stress during pregnancy than mothers of unaffected control children. Documenting the role of comorbidity in the heterogeneity of the disorder, findings were less robust when ADHD was comorbid with Tourette syndrome. However, caution should be exercised when interpreting findings that suggest a role of smoking during pregnancy in the etiology of ADHD, since several other studies found neither an association nor an impact of maternal smoking during pregnancy in attentional control (see for instance, [1, 12]). $\mathrm{Li}$ et al. [6] assessed a nationwide population-based cohort sample including all 1,015,912 singletons born in Denmark from 1987 to 2001 to assess the role of prenatal maternal exposure to bereavement in ADHD. They found that boys born to mothers who lost a child or spouse in the 6 months before pregnancy or during pregnancy had significantly increased risk for ADHD.

Finally, Jepsen et al. [4] assessed some neuropsychological aspects of executive functioning and attention in two groups of early-onset patients with psychosis and in 
healthy controls in a 5-year follow-up study. They found evidence for post-onset developmental deficits in some aspects of attention and executive functions in patients with early-onset psychosis. Why does this finding matter for ADHD? They again remind us that neuropsychological deficits in the trajectory of attention and executive functions are not specific for ADHD, showing the complexity of searching for neuropsychological deficits whose performance is good enough for them to be incorporated in the ADHD criteria in new classificatory systems!

Conflicts of interest Dr. Rohde was on the speakers' bureau and/or acted as consultant for Eli Lilly, Janssen-Cilag, Novartis and Shire in the past 3 years (less than U\$ 10,000 per year and reflecting less than $5 \%$ of his gross income per year). He also received travel awards (air tickets + hotel) from Novartis and Janssen-Cilag for taking part in two child psychiatric meetings. The ADHD and Juvenile Bipolar Disorder Outpatient Programs chaired by him received unrestricted educational and research support from the following pharmaceutical companies in the past 3 years: Abbott, Bristol-Myers Squibb, Eli Lilly, Janssen-Cilag, Novartis, and Shire.

\section{References}

1. Altink ME, Slaats-Willemse DI, Rommelse NN, Buschgens CJ, Fliers EA, Arias-Vasquez A, Xu X, Franke B, Sergeant JA, Faraone SV, Buitelaar JK (2009) Effects of maternal and paternal smoking on attentional control in children with and without ADHD. Eur Child Adolesc Psychiatry 18:465-475

2. Ghanizadeh A (2010) Factor analysis on ADHD and autism spectrum disorder DSM-IV-derived items shows lack of overlap. Eur Child Adolesc Psychiatry. doi:10.1007/s00787-010-0127-3

3. Hyman SE (2007) Can neuroscience be integrated into the DSMV? Nat Rev Neurosci 8:725-732

4. Jepsen JRM, Fagerlund B, Pagsberg AK, Christensen AMR, Nordentoft M, Mortensen EL (2010) Deficient maturation of aspects of attention and executive functions in early onset schizophrenia. Eur Child Adolesc Psychiatry. doi:10.1007/s00787010-0126-4

5. Langley K, Fowler TA, Grady DL, Moyzis RK, Holmans PA, van den Bree MB, Owen MJ, O'Donovan MC, Thapar A (2008) Molecular genetic contribution to the developmental course of attention-deficit hyperactivity disorder. Eur Child Adolesc Psychiatry $18: 26-32$

6. Li J, Olsen J, Vestergaard M, Obel C (2010) Attention-deficit/ hyperactivity disorder in the offspring following prenatal maternal bereavement: a nationwide follow-up study in Denmark. Eur Child Adolesc Psychiatry. doi:10.1007/s00787-010-0113-9

7. López-Muñoz F, Alamo C, Quintero-Gutiérrez FJ, García-García P (2008) A bibliometric study of international scientific productivity in attention-deficit hyperactivity disorder covering the period 1980-2005. Eur Child Adolesc Psychiatry 17:381-391

8. Motlagh MG, Katsovich L, Thompson N, Lin H, Kim Y-S, Scahill L, Lombroso PJ, King RA, Peterson BS, Leckman JF (2010) Severe psychosocial stress and heavy cigarette smoking during pregnancy: an examination of the pre- and perinatal risk factors associated with ADHD and Tourette syndrome. Eur Child Adolesc Psychiatry. doi:10.1007/s00787-010-0115-7

9. Polanczyk G, Silva de Lima M, Horta BH, Biederman J, Rohde LA (2007) The worldwide prevalence of ADHD: a systematic review and metaregression analysis. Am J Psychiatry 164:942948

10. Rohde LA (2008) Is there a need to reformulate attention deficit hyperactivity disorder criteria in future nosologic classifications? Child Adolesc Psychiatric Clin N Am 17:405-420

11. Sinzig J, Morsch D, Lehmkuhl G (2008) Do hyperactivity, impulsivity and inattention have an impact on the ability of facial affect recognition in children with autism and ADHD? Eur Child Adolesc Psychiatry 17:63-72

12. Thapar A, Rice F, Hay D, Boivin J, Langley K, van den Bree M, Rutter M, Harold G (2009) Prenatal smoking might not cause attention-deficit/hyperactivity disorder: evidence from a novel design. Biol Psychiatry 66:722-727

13. Tripp G, Wickens JR (2009) Neurobiology of ADHD. Neuropharmacology 57:579-589 